\title{
Bócio congênito em caprinos no Noroeste do Rio Grande do Sul, Brasil
}

\author{
Congenital caprine goiter in northwestern Rio Grande do Sul state, Brazil
}

Welden Panziera ${ }^{I}$ Ananda Paula KowalskiI ${ }^{I I}$ Glauco José Nogueira de Galiza Ronaldo Michel Bianchi ${ }^{\mathrm{I}}$ Julia Pires Espíndola ${ }^{\mathrm{II}}$ Maurício Machado Cardoso ${ }^{\mathrm{II}}$ Agueda Castagna de Vargas $^{\text {II }}$ Rafael Almeida Fighera ${ }^{\text {IV }}$

\begin{abstract}
Os aspectos epidemiológicos, clínicos e anatomopatológicos de um surto de bócio congênito em caprinos são descritos. A etiologia dessa condição foi associada à ausência de suplementação mineral com iodo para as cabras prenhes, e constituiu o fator responsável pela natimortalidade nesse surto. Clinicamente, todos os natimortos apresentaram marcado aumento de volume na região cervical ventral cranial e alopecia difusa. Na necropsia de um dos cabritos natimortos, observouse acentuado aumento de volume simétrico de ambos os lobos da glândula tireoide, que eram firmes, compactos e vermelhoescuros. Histologicamente, as lesões eram características de bócio hiperplásico difuso e consistiam de: 1) marcada hiperplasia e hipertrofia do epitélio folicular; 2) formação de folículos tireoidianos marcadamente heterogêneos, devido principalmente à quantidade variável de coloide intraluminal; $e$ 3) presença de vacúolos endocíticos, que representam a endocitose do coloide e demonstram a atividade da glândula tireoide.
\end{abstract}

Palavras-chave: doenças de caprinos, bócio hiperplásico, deficiencia de iodo, anormalidades congênitas.

\section{ABSTRACT}

The epidemiological, clinical, and anatomopathological aspects of an outbreak of congenital caprine goiter are described in this article. The cause of the congenital goiter and neonatal deaths was attributed to the absence of mineral supplementation with iodine to the pregnant dams. Clinically, all neonatal dead goats presented with marked swelling on the cranioventral cervical area and diffuse body alopecia. One of the dead kids was submitted to necropsy, and changes consisted of marked, symmetrical enlargement of both thyroid lobes, which were also firm, compact, and dark red. Histologically, changes were characteristic of diffuse hyperplastic goiter and consisted of: 1) marked follicular thyroid hyperplasia and hypertrophy; 2) formation of heterogeneous thyroid follicles due to the variable amounts of luminal colloid; and 3) presence of endocytic vacuoles, which represent colloid endocytosis and demonstrate activity of the thyroid gland.

Key words: diseases of goats, hyperplastic goiter, iodine deficiency, congenital anomalies.

Bócio é um termo clínico utilizado para descrever um aumento de volume não neoplásico e não inflamatório da glândula tireoide, que acomete mamíferos domésticos, marinhos e silvestres, além de aves e humanos (CAPEN, 2007; ECCO \& LANGOHR, 2010; LA PERLE, 2013). O bócio congênito, aquele que é observado quando o indivíduo nasce com a condição, tem sido a apresentação da doença mais frequentemente vista em caprinos, embora sejam poucas as descrições (AL-ANI et al., 1998; OZMEN et al., 2005; CHEEMA et al., 2010). Além dessa espécie, essa condição é descrita com certa frequência em ovinos, bovinos e equinos (CAPEN, 2007; RADOSTITS et al., 2007; RIETCORREA, 2007; LA PERLE, 2013; TOKARNIA et al., 2010). Os animais acometidos apresentam um variável aumento de volume na região cervical ventral cranial, associado a diferentes graus de alopecia e mixedema (CAPEN, 2007).

\footnotetext{
IPrograma de Pós-graduação em Medicina Veterinária, área de concentração em Patologia e Patologia Clínica, Centro de Ciências Rurais (CCR), Universidade Federal de Santa Maria (UFSM), Bairro Camobi, Santa Maria, RS, Brasil.

IIDepartamento de Medicina Veterinária Preventiva, CCR, UFSM, Santa Maria, RS, Brasil.

${ }^{\text {IIIC } C u r s o ~ d e ~ M e d i c i n a ~ V e t e r i n a ́ r i a, ~ C C R, ~ U F S M, ~ S a n t a ~ M a r i a, ~ R S, ~ B r a s i l ~}$

${ }^{\text {IV }}$ Departamento de Patologia, Centro de Ciências da Saúde (CCS), UFSM, Av. Roraima 1000, Santa Maria, RS 97105-900. E-mail: anemiaveterinaria@yahoo.com.br. Autor para correspondência.
} 
No bócio congênito, o aumento de volume da glândula tireoide é difuso e reflete o comprometimento da síntese dos hormônios tireoidianos (ECCO \& LANGOHR, 2010). Os mecanismos patogênicos responsáveis pelo desenvolvimento dessa condição incluem deficiência ou excesso de iodo na dieta, compostos bociogênicos que interferem na absorção de iodo pela tireoide e um defeito genético nas enzimas responsáveis pela síntese dos hormônios tireoidianos (CAPEN, 2007; LA PERLE, 2013). Todos estes fatores resultam em síntese inadequada de triiodotironina (T3) e tiroxina (T4), com subsequente diminuição nas concentrações séricas desses hormônios, o que estimula o hipotálamo e, por conseguinte, a hipófise, a secretar hormônio tireoestimulante (TSH). Com isso, ocorre hipertrofia e hiperplasia das células foliculares da glândula tireoide (LA PERLE, 2013).

O objetivo deste trabalho é relatar um surto de bócio congênito em caprinos, abordando seus aspectos epidemiológicos, clínicos e anatomopatológicos.

Um feto caprino, macho, sem raça definida, proveniente do município de Rondinha, localizado no noroeste do estado do Rio Grande do Sul, no sul do Brasil, foi remetido para o Laboratório de Patologia Veterinária da Universidade Federal de Santa Maria (LPV-UFSM). O feto foi submetido para avaliação anatomopatológica, pois, na propriedade rural em questão, as cabras pariam com extrema dificuldade, e os cabritos nasciam mortos e apresentavam grande aumento de volume na região cervical ventral cranial.

Na propriedade, havia 20 caprinos sem raça definida, dos quais 15 eram fêmeas adultas, quatro eram caprinos jovens e um era macho adulto (bode). Todos os caprinos viviam em conjunto, em sistema de semi-confinamento, e o reprodutor era substituído anualmente, a fim de evitar consanguinidade. Não tinham acesso à suplementação mineral e a água da propriedade era proveniente de um poço artesiano.

No outono de 2013, entre março e maio, das 15 cabras prenhes, 10 pariram cabritos mortos. Dessas 10 cabras, seis morreram em decorrência de parto distócico. As quatro cabras que sobreviveram desenvolveram retenção de placenta. O parto das outras cinco cabras foi normal. Segundo informações do proprietário, 2013 foi o segundo ano em que ocorreram casos de natimortalidade na propriedade.

$\mathrm{Na}$ necropsia, o cabrito natimorto apresentava alopecia difusa e acentuado aumento de volume simétrico de ambos os lobos da glândula tireoide (Figura 1a). Os lobos eram firmes, compactos e vermelho-escuros. No tecido subcutâneo da região cervical ventral, caudalmente à glândula tireoide aumentada, observou-se uma área focalmente extensa de hemorragia, possivelmente oriunda das manobras obstétricas realizadas pelo veterinário durante o parto.

Histologicamente, havia marcada hiperplasia folicular com notável heterogeneidade de tamanho entre os folículos (Figura 1b). Numerosos folículos estavam preenchidos por quantidade variável de coloide levemente eosinofílico, que, por vezes, apresentava pequenos vacúolos próximos ao epitélio de revestimento (vacúolos endocíticos) (Figura 1c). Todos os folículos eram delineados por um epitélio cúbico alto hipertrofiado de 1-3 camadas de células. A maior parte das células que revestiam os folículos tinha o citoplasma leve a moderadamente eosinofílico e variavelmente vacuolizado. O núcleo dessas células era formado por cromatina frouxa, rechaçado basalmente e com nucléolo inconspícuo (Figura 1d). A minoria das células demonstrava núcleos com a cromatina mais agregada e sem nucléolo. Em todos os folículos havia poucas células em apoptose. Poucos folículos não apresentavam coloide e o epitélio de revestimento era hiperplásico, na forma de projeções intraluminais.

Os sinais clínicos, as lesões macroscópicas e os achados histológicos observados nestes casos são idênticos àqueles previamente descritos (AL-ANI et al., 1998; OZMEN et al., 2005; CHEEMA et al., 2010) para bócio congênito e constituem evidências que permitem o diagnóstico definitivo desta condição.

Bócio é a principal anormalidade congênita de caprinos em várias partes do mundo, entretanto, os casos são esporádicos (CAPEN, 2007; LA PERLE, 2013). Relatos de bócio em caprinos são escassos no Brasil (ALMEIDA et al., 2013) e, em nossa rotina, nenhum surto de bócio congênito em caprinos havia sido descrito até então (ROSA et al., 2013).

A etiologia do bócio congênito neste surto estava associada à ausência de suplementação mineral com iodo para as cabras. Para a maior parte dos autores (CAPEN, 2007; RADOSTITS et al., 2007; TOKARNIA et al., 2010; LA PERLE, 2013), a prole de fêmeas alimentadas com dietas pobres em iodo tem maior probabilidade em desenvolver esta condição. $\mathrm{O}$ iodo possui participação fundamental na síntese dos hormônios tireoidianos (T3 e T4) e sua deficiência constitui a principal causa de bócio em animais domésticos (ECCO \& LANGOHR, 2010; LA PERLE, 2013).

Clinicamente, todos os caprinos natimortos apresentaram sinais típicos de bócio congênito, que consistiam de acentuado aumento de volume palpável na região cervical ventral cranial e alopecia difusa. 


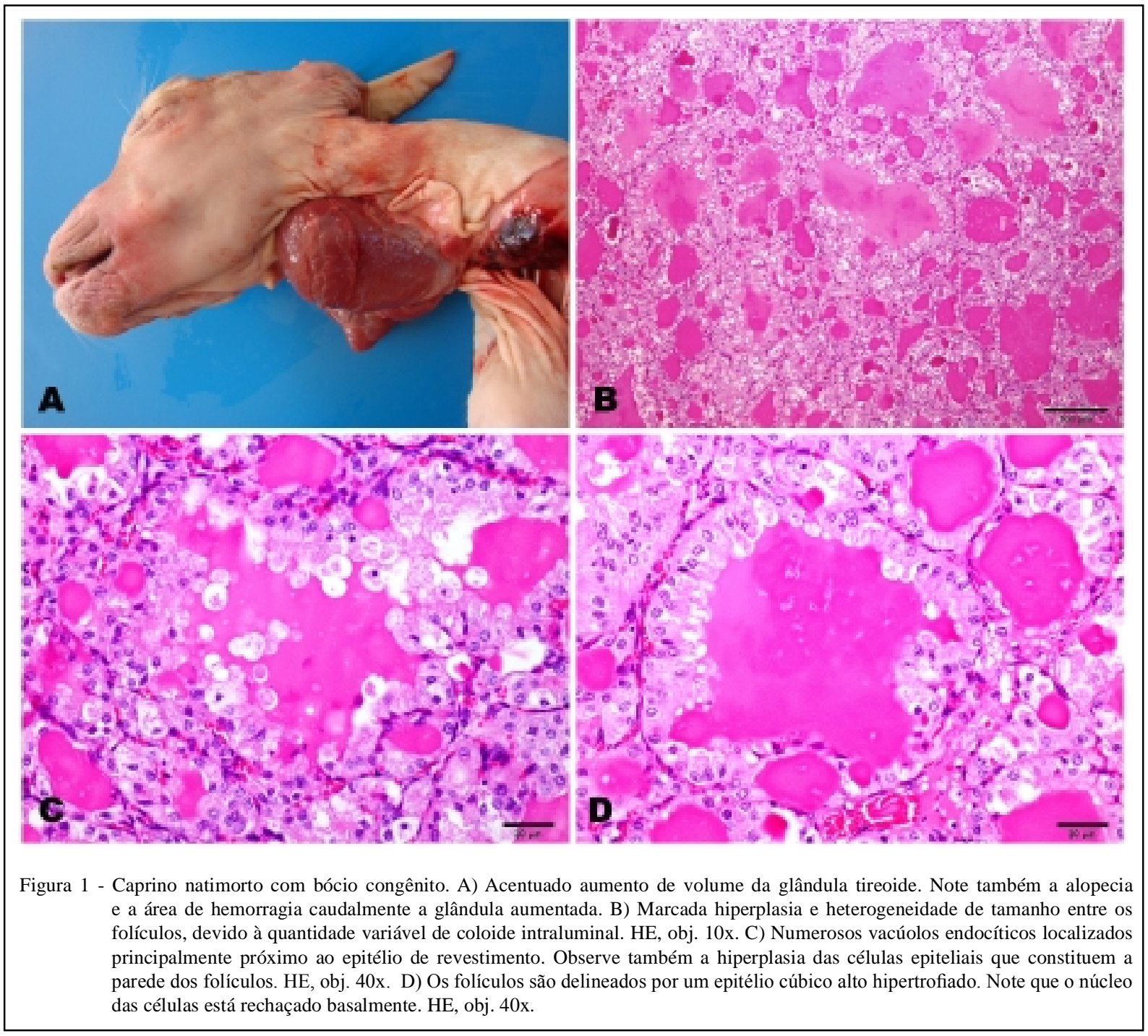

Além disso, os natimortos eram acentuadamente magros. Esses sinais constituem os principais achados clínicos descritos em casos de bócio (AL-ANI et al., 1998; RUFFIN et al., 2002; OZMEN et al., 2005; RADOSTITS et al., 2007; RIET-CORREA, 2007; CHEEMA et al., 2010; TOKARNIA et al., 2010). Outro sinal clínico importante, e que pode ocorrer com certa frequência, é o mixedema (RUFFIN et al., 2002; CAPEN, 2007; CHEEMA et al., 2010), não observado nestes casos.

Os achados macroscópicos e histopatológicos também são idênticos aos descritos para bócio congênito, principalmente para o tipo hiperplásico difuso, que representa a forma mais comum de bócio congênito em caprinos (JONES et al., 2000; CAPEN, 2007; ECCO \& LANGOHR, 2010; LA PERLE, 2013). O acentuado aumento de volume difuso de ambos os lobos da tireoide é característico dessa condição. Histologicamente, o bócio hiperplásico caracteriza-se pela marcada diferença no tamanho e formato dos folículos, devido à quantidade variável de coloide intraluminal (ECCO \& LANGOHR, 2010) e pelo revestimento folicular por uma ou mais camadas de células epiteliais cúbicas altas ou cilíndricas, por vezes, formando projeções papilares (CAPEN, 2007), idêntico ao evidenciado no caprino desse caso. Outra característica importante, e que também foi observada neste caso, é a presença de vacúolos endocíticos, que representam a endocitose do coloide e demonstram a atividade da glândula tireoide (LA PERLE, 2013).

O diagnóstico de bócio congênito neste surto foi baseado nos dados epidemiológicos, nos sinais clínicos relatados pelo veterinário e proprietário e nos achados anatomopatológicos. A principal medida profilática para evitar casos de

Ciência Rural, v.44, n.12, dez, 2014. 
bócio em caprinos é fornecer suplementação mineral com iodo para todo o rebanho (RUFFIN et al., 2002; RADOSTITS et al., 2007; RIET-CORREA, 2007), o que foi recomendado neste caso.

\section{REFERÊNCIAS}

AL-ANI, F.K. et al. Ocurrence of congenial anomalies in Shami breed goats: 211 cases investigated in 19 herds. Small Ruminant Research, v.28, p.225-232, 1998. Disponível em: <http://www. sciencedirect.com/science/article/pii/S0921448897000904>. Acesso em: 6 mar. 2014. doi: 10.1016/S0921-4488(97)00090-4.

ALMEIDA, A.C.O. et al. Bócio hiperplásico difuso em caprino recém-nascido. In: ENCONTRO NACIONAL DE PATOLOGIA VETERINÁRIA (ENAPAVE), 16., 2013, Curitiba, PR. Anais.. Curitiba: Universidade Federal do Paraná (UFPR) e Associação Brasileira de Patologia Veterinária (ABPV), 2013. V.18. 753p. p.32-33.

CAPEN, C.C. Endocrine glands. In: JUBB, K.V.F. et al. Pathology of domestic animals. 5.ed. Philadelphia: Saunders Elsevier, 2007. 3v. p.325-428.

CHEEMA, A.H. et al. Congenital goiter in goats. Pakistan Veterinary Journal, v.30, p.58-60, 2010. Disponível em: <http:// pvj.com.pk/abstract/30_1/13.htm>. Acesso em: 6 mar. 2014.

ECCO, R.; LANGOHR, I.M. Patologia do sistema endócrino. In: SANTOS, R.L.; ALESSI, A.C. Patologia veterinária. São Paulo: Roca, 2010. p.747-796.
JONES, T.C et al. Patologia veterinária. 6.ed. São Paulo: Manole, 2000. 1414p.

LA PERLE, K.M.D. Sistema endócrino. In: ZACHARY, J.F.; McGAVIN, M.D. Bases da patologia em veterinária. 5.ed. Rio de Janeiro: Elsevier, 2013. p.663-700.

OZMEN, O. et al. Clinical and pathological observations and treatment of congenital goiter in kids. Bulletin of the Veterinary Institute in Pulawy, v.49, p.237-241, 2005. Disponível em: <http://www.piwet.pulawy.pl/doc/ biuletyn_49-2/19_ozmen.pdf?origin=publication_detail $>$. Acesso em: 6 mar. 2014.

RADOSTITS, O.M. et al. Veterinary medicine: a textbook of the diseases of cattle, horses, sheep, pigs and goats. 10.ed. Philadelphia: Saunders Elsevier, 2007. 2156p.

RIET-CORREA, F. Carências minerais. In: RIET-CORREA, et al. Doenças de ruminantes e eqüídeos. 3.ed. Santa Maria: Pallotti, 2007. V. 2, p.223-263.

ROSA, F.B. et al. Doenças de caprinos diagnosticadas na região central do Rio Grande do Sul: 114 casos. Pesquisa Veterinária Brasileira, v.33, p.199-204, 2013.

RUFFIN, D.C. et al. Diseases of the endocrine system. In: PUGH, D.G. Sheep \& goat medicine. Philadelphia: Saunders Elsevier, 2002. p. 187-196.

TOKARNIA, C.H. et al. Deficiências minerais em animais de produção. Rio de Janeiro: Helianthus, 2010. 200p. 